\title{
What Next After Metformin in Type 2 Diabetes? Selecting the Right Drug for the Right Patient
}

\author{
W. David Strain - Carmen Tsang • Michael Hurst - Phil McEwan • \\ Minesh Unadkat · Simon Meadowcroft - Richard Shardlow • \\ Marc Evans
}

Received: March 20, 2020 / Published online: May 18, 2020

(C) The Author(s) 2020

\section{ABSTRACT}

Introduction: Metformin is the recommended initial treatment in type 2 diabetes mellitus (T2DM), but when this does not give adequate glucose control the choice of which second-line drug to use is uncertain as none have been found to have a better overall glycaemic response. In this real-world study dipeptidyl peptidase 4 inhibitors (DPP4i), sulphonylureas (SU), thiazolidinediones (TZD) and sodium

Digital Features To view enhanced digital features for this article go to https://doi.org/10.6084/m9.figshare. 12220364.

Electronic Supplementary Material The online version of this article (https://doi.org/10.1007/s13300020-00834-w) contains supplementary material, which is available to authorized users.

W. D. Strain

Diabetes and Vascular Research Centre, University of Exeter Medical School, Exeter, UK

C. Tsang · M. Hurst · P. McEwan

Health Economics and Outcomes Research Ltd., Cardiff, UK

M. Unadkat $\cdot$ S. Meadowcroft · R. Shardlow

Takeda UK Limited, London, UK

M. Evans $(\square)$

University Hospital Llandough, Cardiff, UK

e-mail: marclyndon1@hotmail.com glucose co-transporter 2 inhibitors (SGLT2i) were compared for their effectiveness in lowering glycated haemoglobin (HbA1c) levels for a particular individual based on their clinical characteristics.

Methods: A retrospective analysis was undertaken of electronic health records of people with T2DM prescribed metformin alongside a DPP4i, SU, TZD or SGLT2i at second-line. Regression modelling was used to model the changes in HbA1c from baseline at month 6 and month 12 for the individual therapies, adjusting for demographic and clinical characteristics. Results: There were 7170 people included in the study. Treatment at second-line with SUs, DPP4i, TZDs and SGLT2i resulted in similar percentages of people achieving the recommended HbA1c target of $<7.5 \%$ $(58 \mathrm{mmol} / \mathrm{mol})$ at both 6 and 12 months. For those receiving SGLT2i and SUs, the greatest improvement in $\mathrm{HbA1c}$ was observed in relatively younger and older people, respectively. Trends were detected between other baseline characteristics and HbA1c improvement by drug class, but they were not statistically significant. Non-adherence rates were low for all drug classes. People with a higher medication possession ratio $(\geq 80 \%)$ also had greater improvements in HbA1c at 12 months.

Conclusion: This study identified patients' phenotypic characteristics that may have the potential to influence individual treatment response. Accounting for these characteristics in 
clinical treatment decisions may facilitate individualised prescribing by being able to select the right drug for the right patient.

Keywords: Dipeptidyl peptidase 4 inhibitor; Glycaemic control; Second-line therapy; Sodium-glucose transporter 2 inhibitor; Sulphonylurea; Thiazolidinedione; Type 2 diabetes mellitus

\section{Key Summary Points}

\section{Why carry out this study?}

Metformin is the recommended initial treatment in type 2 diabetes mellitus (T2DM), and when this does not give adequate glucose control the American Diabetes Association (ADA) and the European Association for the Study of Diabetes (EASD) guidelines provide second-line therapy recommendations based on the presence of established chronic kidney disease, heart failure or atherosclerotic cardiovascular disease.

The majority of people with T2DM do not have these comorbidities, and for these people there is uncertainty within the clinical community around the optimal choice of second-line treatment, as none have been found to have a better overall glycaemic response.

In this study, the real-world efficacy profiles of dipeptidyl peptidase 4 inhibitors (DPP4i), sulphonylureas (SU), thiazolidinediones (TZD) and sodium glucose co-transporter 2 inhibitors (SGLT2i) following metformin monotherapy were examined in terms of glycaemic control as a function of baseline phenotypic characteristics at second-line initiation.

\section{What was learned from the study?}

The study found little difference in the glycaemic effects of the different drug classes at 6 and 12 months.
However, patients' age may have the potential to influence treatment response. In addition, other phenotypic characteristics such as gender, body mass index, estimated glomerular filtration rate (eGFR) and duration of T2DM may also be associated with $\mathrm{HbA1c}$ response but further research is required to examine these trends.

Accounting for specific demographic and clinical characteristics in clinical treatment decisions will enable better targeting of second-line regimens according to a person's individual profile to achieve optimal clinical outcomes.

\section{INTRODUCTION}

Type 2 diabetes (T2DM) is characterised by insulin resistance, progressive decline in $\beta$-cell function and associated hyperglycaemia. Glycated haemoglobin (HbA1c) remains the gold standard for monitoring glycaemic control, albeit with the limitations that it only measures average glucose concentration and cannot report glycaemic excursions or frequency of hypoglycaemia [1]. Recent cardiovascular outcome trials (CVOTs) have focused on macrovascular complications in later diabetes; however, microvascular complications, present in approximately $54 \%$ of the total population with diabetes [2], also represent a significant clinical burden [3]. Microvascular complications such as blindness, renal failure and diabetic foot disease are associated with poor quality of life [4] and are amongst the greatest concerns for people with T2DM [5-7]. Optimised glycaemic control to the recommended HbA1c target of $7 \%(53 \mathrm{mmol} / \mathrm{mol}) \quad[8,9]$ remains the optimum strategy for minimising the risk of these microvascular complications as well as limiting progression of some macrovascular complications (notably stroke, congestive heart failure, peripheral vascular disease) [10-12].

Large randomised trials and prospective observational studies have demonstrated that 
the level of achieved glycaemic control, rather than the agent used, is the predictor of incidence and delayed progression of microvascular complications in early T2DM [12-17]. There are an increasing number of effective oral hypoglycaemic agents (OHAs) for improving glycaemic control in T2DM. It is widely accepted that most people with T2DM should receive metformin at first line because of its efficacy in reducing plasma glucose without increasing the risks of hypoglycaemia or weight gain $[18,19]$. When metformin monotherapy fails to achieve glycaemic control, or the disease progresses such that glycaemia rises, a second drug will need to be added to metformin $[8,9]$. The most recent consensus report by the American Diabetes Association (ADA) and the European Association for the Study of Diabetes (EASD) includes therapy recommendations based on the presence of comorbidities. These guidelines recommend the addition of a sodium glucose co-transporter 2 inhibitor (SGLT2i) or glucagonlike peptide-1 (GLP1) receptor antagonist following metformin monotherapy, irrespective of HbA1c level, in people with established chronic kidney disease (CKD), heart failure (HF) or atherosclerotic cardiovascular disease (ACVD) [20]. However, the majority of people with T2DM do not have these comorbidities. For these people, given that CVOTs have failed to show significant benefits in major adverse cardiovascular events (MACE) with any specific OHA [21-24], there is uncertainty within the clinical community around the optimal choice of second-line drug. Current National Institute for Health and Care Excellence (NICE) clinical guidelines recommend that treatment should be intensified if $\mathrm{HbA} 1 \mathrm{c}$ rises to $7.5 \%$ $(58 \mathrm{mmol} / \mathrm{mol})$ or higher with metformin monotherapy [8]. In these cases, metformin should be combined with a drug from one of four drug classes: a sulphonylurea (SU), thiazolidinedione (TZD), dipeptidyl peptidase 4 inhibitor (DPP4i) or SGLT2i [8]. However, the guidelines do not indicate which drug should be prescribed over other drugs for individuals according to their unique demographic and clinical profiles. Instead, the guidelines recommend that treatment decisions be based on factors such as efficacy, safety, tolerability, individual clinical circumstances, preferences and needs, available licensed indications and cost [8]. If more than one drug in the same class is suitable, the drug with the lowest acquisition cost should be prescribed [8].

Meta-analyses comparing the effectiveness of the different drug classes have demonstrated similar clinically meaningful reductions in $\mathrm{HbA1c}$ for all classes of second-line drugs when they are added to metformin as dual therapy, but with differences in weight gain and risk of hypoglycaemia [25-27]. However, the realworld effectiveness of these drugs in routine clinical practice is less well understood. The purpose of this study was to explore the realworld efficacy profiles of OHAs following metformin monotherapy in terms of glycaemic control as a function of baseline phenotypic characteristics. By using data collected from routine primary care practice, the study will generate valuable evidence that is currently lacking to inform clinical decision making on the management of people with T2DM who have failed metformin monotherapy. A better understanding of patient profiles and treatment practices may lead to improved disease management through better targeting of second-line regimens according to demographic and clinical characteristics to achieve optimal clinical outcomes.

\section{METHODS}

\section{Study Design}

This was a retrospective cohort study using data obtained from the Clinical Practice Research Datalink (CPRD) GOLD database [28], which contains electronic health records of approximately 11.3 million patients ( 4.4 million active) across 674 primary care practices in the UK. The study data set consisted of adult patients ( $\geq 18$ years) diagnosed with T2DM (diagnosis defined as the presence of a Read code specific to T2DM in the patient records). Patients were eligible for study inclusion if they were prescribed metformin as first-line treatment for T2DM and subsequently received a SU, DPP4i, TZD or SGLT2i at second-line (as dual therapy 
in combination with metformin). Relevant prescription records were identified for each patient by examining British National Formulary (BNF) codes for anti-diabetic drugs.

The index date for each person was the date of first prescription of the second-line regimen. Data were extracted for the period between 1 January 2002 and 31 December 2017, with a study index period between 1 January 2012 and 31 December 2016. People were followed up to the earliest of death, end of study, 2-year post index or loss to follow-up (LTFU). LTFU was defined as the earliest of person transferred out of GP practice, practice left CPRD or last recorded measurement.

This was a retrospective observational study using anonymised data from CPRD, which holds ethical approval for observational studies. The Independent Scientific Advisory Committee for Medicines and Healthcare Products Regulatory Agency approved this study (19_078RAR). Subsequent amendments were approved by ISAC on 18 March 2020 (ISAC protocol reference 19_078RAR).

\section{Study Population}

In this study, people were diagnosed with T2DM between 1 January 2002 and 31 December 2016 and were initially prescribed metformin. They subsequently had the addition of a SU, DPP4i, TZD or SGLT2i between 1 January 2012 and 31 December 2016. Individuals were required to be on a stable dose of metformin for at least 3 months prior to intensification to dual therapy and first prescribed a SU, DPP4i, TZD or SGLT2i at least 12 months prior to data cut-off.

People previously (prior to T2DM diagnosis) treated with any antidiabetic medication other than metformin, with pre-existing ACVD (heart failure, ischaemic heart disease, peripheral artery disease, stroke, myocardial infarction, transient ischaemic attack, coronary artery stenosis or angina, for whom guidelines would suggest SGLT2i and/or GLP1 receptor agonists should be the treatment of choice), aged $<18$ years on T2DM diagnosis date, without a HbA1c measurement at baseline or with HbA1c $>10 \%$ at baseline, or with $<1$ year of follow-up after dual therapy initiation were excluded from the study.

\section{Study Outcomes}

HbA1c change from baseline was the primary study outcome. Additional study outcomes included rates of discontinuation (treatment switch/cessation) and treatment intensification (addition of a new drug to second-line dual therapy) at 6 and 12 months post-baseline, rates of incident adverse events (AEs) during the study period at 12 months post-baseline and medication possession ratio (MPR) across second-line drugs (calculated as the number of days of prescription coverage [quantity of dosage prescribed divided by the daily dose] divided by the length of the follow-up period). Adherence was defined as an $\mathrm{MPR} \geq 80 \%$; individuals with an MPR $<20 \%$ were excluded $[29,30]$.

\section{Statistical Analysis}

Summary descriptive statistics were calculated for the overall study population and stratified by baseline HbA1c. These statistics characterised demographic, clinical and treatment characteristics, and medication use. Missing values at baseline were recorded as such for each variable. Regression modelling was used to model the changes in HbA1c at month 6 and month 12 for each of the individual therapies. Initial 6- and 12-month models were fitted to the full data with backwards stepwise regression used for variable selection. This ensured each therapy model was adjusting for a consistent set of characteristics. The extent of missingness in each variable was reviewed to inform decisions about variable inclusion in the models. Variables with $>40 \%$ missingness were excluded from the modelling process. Baseline HbA1c was included in as a covariate in each of the models. Models were fitted to the data to adjust for the effect of observed covariates (potential confounders) including demographic characteristics, clinical factors, concomitant prescriptions and comorbidities. 
To explore the factors associated with change in HbA1c in unadjusted analyses, the change was grouped into equal tertiles which represent the people with the smallest drop in HbA1c, medium size drop in HbA1c and the greatest drop in HbA1c. The mean and 95\% confidence intervals (CI) of change for each factor were calculated within each tertile to show the differences in characteristics for different levels of change. Adverse event rates were calculated for each second-line therapy. Only the first event of each type and person time up to that event per person contributed to the calculations of the event rates. All analyses were performed using $\mathrm{R}$ version 3.4 or later.

\section{RESULTS}

\section{Baseline Demographic and Clinical Characteristics}

In this study, we identified 7170 people with T2DM in the CPRD data set who received firstline metformin monotherapy and were subsequently initiated on second-line treatment and who met the study inclusion criteria (Figure S1). The baseline characteristics of the people included in analyses are shown in Table 1. Overall, $59.69 \%$ of people were male, the mean age at T2DM diagnosis was 56.09 years and the mean $\mathrm{HbA1c}$ at baseline was $8.34 \%$. SUs were the most common second-line treatment prescribed in addition to metformin (49.11\%), followed by DPP4i (41.58\%), SGLT2i $(6.83 \%)$ and TZDs (2.48\%). Individuals' characteristics at baseline varied by drug class. For example, people initiated on an SGLT2i were relatively younger with fewer comorbidities than people initiated on other second-line therapies, but with heavier body weight and greater body mass index (BMI).

\section{Factors Associated with Drug Response}

At 12 months post-baseline (Fig. 1), SGLT2i appeared to be most potent in relatively younger males with lower BMI and high diastolic blood pressure (DBP). SUs, however, demonstrated the greatest improvement in relatively older males with lower BMI and lower estimated glomerular filtration (eGFR) rate. Males with higher DBP and SBP but lower eGFR benefitted most from DPP4i. However, only the trends in patient age for SGLT2i and SUs were statistically significant. TZDs gave consistent results in all individuals irrespective of baseline characteristics, with baseline HbA1c being the only predictive factor.

\section{Change in HbA1c from Baseline}

Mean HbA1c at baseline was similar among people receiving a SU, DPP4i, TZD or SGLT2i at second-line $(8.40 \%, 8.26 \%, 8.37 \%$ and $8.38 \%$ respectively) (Table 2). At 6 and 12 months, over half of people who were still on therapy achieved a HbA1c $<7.5 \%$ in each drug class. This ranged from $58.90 \%$ for SGLT2i to $70.14 \%$ for SUs at 6 months and from $60.56 \%$ for SUs to $67.44 \%$ for SGLT2i at 12 months. However, as SGLT2i, TZD and SU therapies were initiated in people with incrementally higher baseline HbA1c, there were greater improvements in HbA1c for these individuals over the study period (Table S1). For example, in people still on therapy at 12 months, there was a mean reduction of $1.08 \% \quad(12 \mathrm{mmol} / \mathrm{mol}), \quad 0.99 \%$ $(11 \mathrm{mmol} / \mathrm{mol})$ and $0.97 \%(10 \mathrm{mmol} / \mathrm{mol})$ for individuals who had received a SGLT2i, TZD or $\mathrm{SU}$, respectively, compared with mean reduction of $0.74 \%(8 \mathrm{mmol} / \mathrm{mol})$ for individuals who had received a DPP4i (Table 2). The distributions of change in HbA1c from baseline at 6 and 12 months were similar across the four drug classes (Figure S2).

After variable reduction was performed, the 6- and 12-month models were fitted to each drug class. Baseline HbA1c, age, BMI, systolic blood pressure (SBP) and sex were present within both the 6- and 12-month models. Triglycerides were present in the 6-month model only; total cholesterol and ethnicity were present in the 12-month model only. After adjusting for these demographic and baseline clinical characteristics, regardless of drug class, people with higher HbA1c at baseline and remaining on therapy achieved greater 
Table 1 Baseline patient demographic and clinical characteristics

\begin{tabular}{|c|c|c|c|c|c|}
\hline Characteristic & $\begin{array}{l}\text { Overall } \\
(N=7170)\end{array}$ & SU $(N=3521)$ & $\begin{array}{l}\text { DPP4i } \\
(N=2981)\end{array}$ & $\begin{array}{l}\text { TZD } \\
(N=178)\end{array}$ & $\begin{array}{l}\text { SGLT2i } \\
(N=490)\end{array}$ \\
\hline \multicolumn{6}{|l|}{ Age in years, mean $(\mathrm{SD})$} \\
\hline At T2DM diagnosis & $56.09(10.91)$ & $56.79(11.23)$ & $56.01(10.54)$ & $54.87(12.10)$ & $52.04(9.33)$ \\
\hline $\begin{array}{l}\text { At second-line therapy } \\
\text { initiation }\end{array}$ & $60.57(11.53)$ & $61.19(11.83)$ & $60.61(11.19)$ & $59.44(12.86)$ & $56.25(9.80)$ \\
\hline \multicolumn{6}{|l|}{ Gender, $n(\%)$} \\
\hline Male & $4280(59.69 \%)$ & $2100(59.64 \%)$ & $1789(60.01 \%)$ & $116(65.17 \%)$ & $275(56.12 \%)$ \\
\hline \multicolumn{6}{|l|}{ Ethnicity, $n(\%)$} \\
\hline White & $1137(15.86 \%)$ & 597 (16.96\%) & 447 (14.99\%) & 38 (21.35\%) & 55 (11.22\%) \\
\hline Other & $91(1.27 \%)$ & $50(1.42 \%)$ & $35(1.17 \%)$ & $<5^{*}$ & $<5^{*}$ \\
\hline Not recorded & $5942(82.87 \%)$ & $2874(81.62 \%)$ & $2499(83.83 \%)$ & $137(76.97 \%)$ & $432(88.16 \%)$ \\
\hline \multicolumn{6}{|l|}{ Smoking status, $n$ (\%) } \\
\hline Current smoker & $1095(15.27 \%)$ & $559(15.88 \%)$ & $425(14.26 \%)$ & $34(19.10 \%)$ & $77(15.71 \%)$ \\
\hline Former smoker & $2562(35.73 \%)$ & $1266(35.96 \%)$ & $1073(35.99 \%)$ & $53(29.78 \%)$ & $170(34.69 \%)$ \\
\hline Passive smoker & $14(0.20 \%)$ & $<5^{*}$ & $10(0.34 \%)$ & $0(0.00 \%)$ & $<5^{*}$ \\
\hline Non-smoker & $3453(48.16 \%)$ & $1669(47.40 \%)$ & $1456(48.84 \%)$ & $90(50.56 \%)$ & $238(48.57 \%)$ \\
\hline Not recorded & $46(0.64 \%)$ & $25(0.71 \%)$ & $17(0.57 \%)$ & $<5^{*}$ & $<5^{*}$ \\
\hline \multicolumn{6}{|c|}{ Duration of T2DM in years, mean (SD) } \\
\hline $\begin{array}{l}\text { At second-line therapy } \\
\text { initiation }\end{array}$ & $4.47(2.98)$ & $4.41(2.98)$ & $4.59(2.96)$ & $4.57(3.18)$ & $4.21(3.01)$ \\
\hline \multicolumn{6}{|c|}{ Clinical measurements (latest value $\leq 6$ months prior to second-line initiation) } \\
\hline \multicolumn{6}{|l|}{ Height $(\mathrm{m})$} \\
\hline$n(\%)$ & $1708(23.82 \%)$ & $852(24.20 \%)$ & $733(24.59 \%)$ & $34(19.10 \%)$ & $89(18.16 \%)$ \\
\hline Mean (SD) & $1.69(0.10)$ & $1.69(0.10)$ & $1.69(0.10)$ & $1.70(0.10)$ & $1.71(0.10)$ \\
\hline \multicolumn{6}{|l|}{ Weight $(\mathrm{kg})$} \\
\hline$n(\%)$ & $5927(82.66 \%)$ & $2858(81.17 \%)$ & $2504(84.00 \%)$ & $142(79.78 \%)$ & $423(86.33 \%)$ \\
\hline Mean (SD) & $95.55(20.68)$ & $92.65(19.86)$ & $96.91(20.75)$ & $92.25(20.29)$ & $108.16(20.37)$ \\
\hline \multicolumn{6}{|l|}{ BMI $\left(\mathrm{kg} / \mathrm{m}^{2}\right)$} \\
\hline$n(\%)$ & $5893(82.19 \%)$ & $2840(80.66 \%)$ & $2489(83.50 \%)$ & $142(79.78 \%)$ & $422(86.12 \%)$ \\
\hline Mean (SD) & $33.10(6.33)$ & $32.19(6.10)$ & $33.50(6.27)$ & $32.08(5.92)$ & $37.14(6.47)$ \\
\hline \multicolumn{6}{|l|}{ HbAlc [\%] } \\
\hline$n(\%)$ & $7170(100.00 \%)$ & $3521(100.00 \%)$ & $2981(100.00 \%)$ & $178(100.00 \%)$ & $490(100.00 \%)$ \\
\hline Mean (SD) & $8.34(0.78)$ & $8.40(0.78)$ & $8.26(0.76)$ & $8.37(0.81)$ & $8.38(0.80)$ \\
\hline
\end{tabular}


Table 1 continued

\begin{tabular}{|c|c|c|c|c|c|}
\hline Characteristic & $\begin{array}{l}\text { Overall } \\
(N=7170)\end{array}$ & $\mathrm{SU}(N=3521)$ & $\begin{array}{l}\text { DPP4i } \\
(N=2981)\end{array}$ & $\begin{array}{l}\text { TZD } \\
(N=178)\end{array}$ & $\begin{array}{l}\text { SGLT2i } \\
(N=490)\end{array}$ \\
\hline \multicolumn{6}{|l|}{ DBP (mmHg) } \\
\hline$n(\%)$ & $6513(90.84 \%)$ & $3163(89.83 \%)$ & $2747(92.15 \%)$ & $158(88.76 \%)$ & $445(90.82 \%)$ \\
\hline Mean (SD) & $78.21(8.94)$ & $78.12(9.08)$ & $78.12(8.80)$ & $77.23(9.00)$ & $79.80(8.67)$ \\
\hline \multicolumn{6}{|l|}{ SBP (mmHg) } \\
\hline$n(\%)$ & $6513(90.84 \%)$ & $3163(89.83 \%)$ & $2747(92.15 \%)$ & $158(88.76 \%)$ & $445(90.82 \%)$ \\
\hline Mean (SD) & 134.18 (13.97) & $134.25(13.92)$ & $134.02(14.18)$ & $131.87(11.45)$ & $135.51(13.79)$ \\
\hline \multicolumn{6}{|c|}{$\mathrm{eGFR}\left(\mathrm{ml} / \mathrm{min} / 1.73 \mathrm{~m}^{2}\right)$} \\
\hline$n(\%)$ & $2580(35.98 \%)$ & $1174(33.34 \%)$ & $1192(39.99 \%)$ & $54(30.34 \%)$ & $160(32.65 \%)$ \\
\hline Mean (SD) & $71.77(14.83)$ & $71.28(15.09)$ & $71.46(14.62)$ & $71.63(14.66)$ & $77.77(13.13)$ \\
\hline \multicolumn{6}{|l|}{$\mathrm{TC}(\mathrm{mmol} / \mathrm{l})$} \\
\hline$n(\%)$ & $6131(85.51 \%)$ & $2990(84.92 \%)$ & $2569(86.18 \%)$ & $154(86.52 \%)$ & $418(85.31 \%)$ \\
\hline Mean (SD) & $4.29(0.98)$ & $4.31(1.00)$ & $4.26(0.95)$ & $4.32(0.96)$ & $4.38(1.02)$ \\
\hline \multicolumn{6}{|l|}{$\mathrm{HDL}(\mathrm{mmol} / \mathrm{l})$} \\
\hline$n(\%)$ & $5642(78.69 \%)$ & $2696(76.57 \%)$ & 2397 (80.41\%) & $143(80.34 \%)$ & $406(82.86 \%)$ \\
\hline Mean (SD) & $1.16(0.31)$ & $1.17(0.32)$ & $1.16(0.30)$ & $1.11(0.30)$ & $1.14(0.27)$ \\
\hline \multicolumn{6}{|l|}{$\mathrm{LDL}(\mathrm{mmol} / \mathrm{l})$} \\
\hline$n(\%)$ & $4526(63.12 \%)$ & $2102(59.70 \%)$ & $1984(66.55 \%)$ & $108(60.67 \%)$ & $332(67.76 \%)$ \\
\hline Mean (SD) & $2.31(0.93)$ & $2.28(0.92)$ & $2.31(0.91)$ & $2.34(1.07)$ & $2.51(0.96)$ \\
\hline \multicolumn{6}{|l|}{ Triglycerides $(\mathrm{mmol} / \mathrm{l})$} \\
\hline$n(\%)$ & $5022(70.04 \%)$ & $2389(67.85 \%)$ & $2173(72.90 \%)$ & $118(66.29 \%)$ & $342(69.80 \%)$ \\
\hline Mean (SD) & $2.24(1.33)$ & $2.26(1.37)$ & $2.19(1.27)$ & $2.60(2.01)$ & $2.29(1.23)$ \\
\hline \multicolumn{6}{|l|}{ Risk profile, mean (SD) } \\
\hline $\begin{array}{l}\text { Charlson comorbidity } \\
\text { index score }\end{array}$ & $3.85(2.04)$ & $4.01(2.12)$ & $3.78(1.98)$ & $3.51(1.95)$ & $3.29(1.78)$ \\
\hline
\end{tabular}

BMI body mass index, DBP diastolic blood pressure, DPP4i dipeptidyl peptidase 4 inhibitor, eGFR estimated glomerular filtration rate, $H b A 1 c$ glycated haemoglobin, $H D L$ high-density lipoprotein, $L D L$ low-density lipoprotein, $S B P$ systolic blood pressure, $S G L T 2 i$ sodium-glucose transport protein 2 inhibitor, $S U$ sulphonylurea, $T 2 D M$ type 2 diabetes, $T C$ total cholesterol, TZD thiazolidinedione

*Actual value suppressed because of small numbers

improvements in glucose control at 6 and 12 months post-baseline (Fig. 2). At 12 months, SUs demonstrated a loss in potency at higher HbA1c levels, DPP4i and TZDs remained equipotent over the time period, whereas SGLT2i demonstrated a greater effect on glycaemic control in those with highest HbA1c baseline levels (Fig. 2). For people with T2DM 

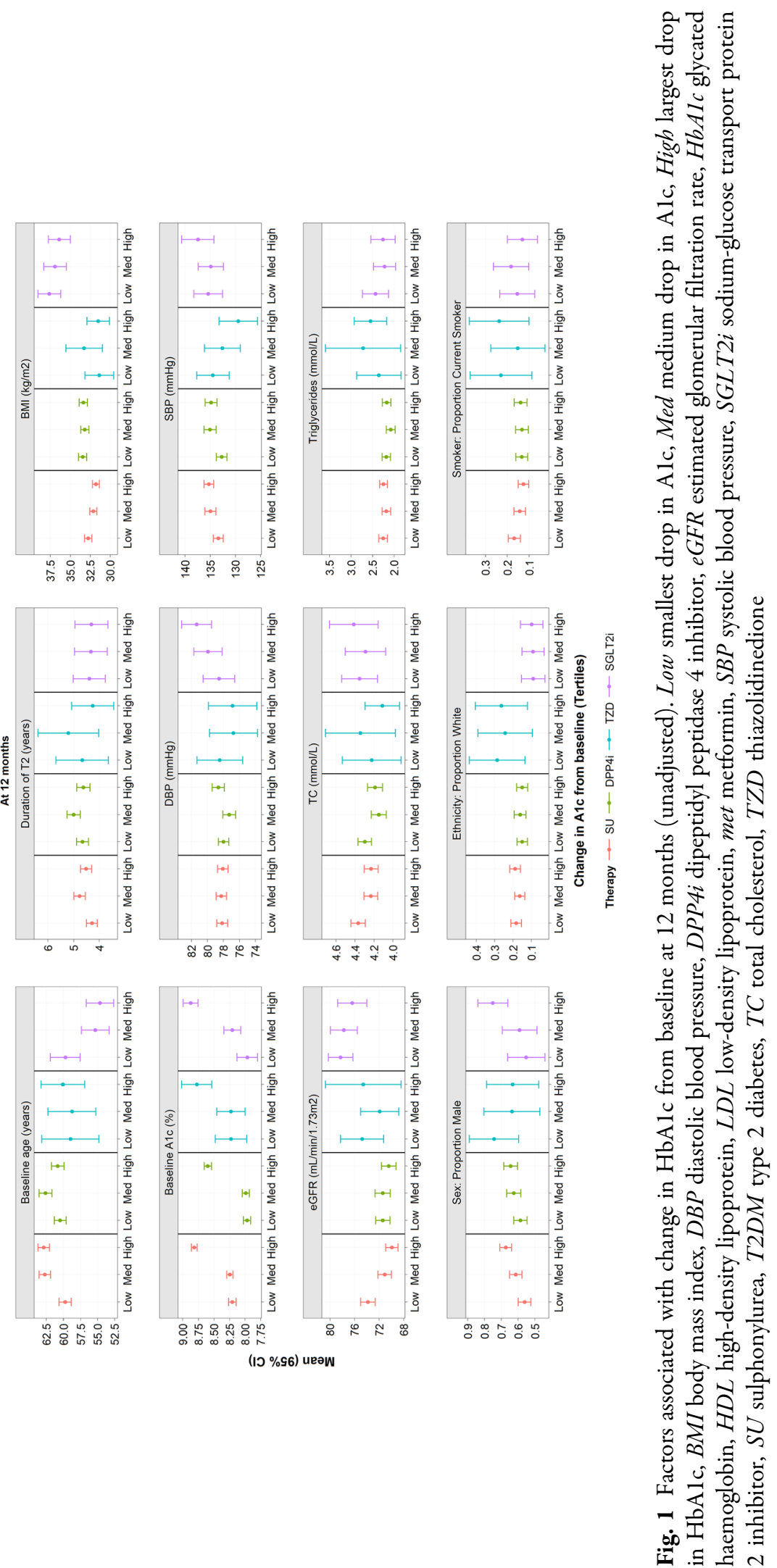
Table 2 Change in HbAlc at 6 months and 12 months from baseline by drug class

\begin{tabular}{|c|c|c|c|c|c|}
\hline & Overall & SU & DPP4i & TZD & SGLT2i \\
\hline \multicolumn{6}{|c|}{ At month 0 (latest value $\leq 6$ months prior to $2 \mathrm{~L}$ initiation) } \\
\hline On second-line therapy, $N$ & 7170 & 3521 & 2981 & 178 & 490 \\
\hline \multicolumn{6}{|c|}{ With measurement HbAlc [\%] } \\
\hline$N(\%)$ & $7170(100.00 \%)$ & $3521(100.00 \%)$ & $2981(100.00 \%)$ & $178(100.00 \%)$ & $490(100.00 \%)$ \\
\hline HbAlc [\%], mean (SD) & $8.34(0.78)$ & $8.40(0.78)$ & $8.26(0.76)$ & $8.37(0.81)$ & $8.38(0.80)$ \\
\hline HbAlc $<7.5 \%, N(\%)$ & $944(13.17 \%)$ & $398(11.30 \%)$ & $460(15.43 \%)$ & $24(13.48 \%)$ & $62(12.65 \%)$ \\
\hline \multicolumn{6}{|l|}{ At month $6^{\mathrm{a}}$} \\
\hline On therapy, $N$ & $6238(87.00 \%)$ & $3103(88.13 \%)$ & $2573(86.31 \%)$ & $155(87.08 \%)$ & $407(83.06 \%)$ \\
\hline \multicolumn{6}{|l|}{ With measurement } \\
\hline$N(\%)$ & $4803(77.00 \%)$ & $2371(76.41 \%)$ & $2008(78.04 \%)$ & $115(74.19 \%)$ & $309(75.92 \%)$ \\
\hline HbAlc [\%], mean (SD) & $7.33(0.97)$ & $7.25(1.01)$ & $7.42(0.93)$ & $7.44(0.91)$ & $7.38(0.79)$ \\
\hline HbAlc $<7.5 \%, N(\%)$ & 3177 (66.15\%) & $1663(70.14 \%)$ & $1261(62.80 \%)$ & $71(61.74 \%)$ & $182(58.90 \%)$ \\
\hline
\end{tabular}

Change at 6 months (for patients with recorded values at initiation and month 6)

Mean $\triangle \mathrm{HbAlc}[\%],(\mathrm{SD}) \quad-1.01(0.98) \quad-1.18(1.05) \quad-0.81(0.89) \quad-0.98(0.82) \quad-1.03(0.86)$

At month $12^{\mathrm{b}}$

On therapy, $N$

$$
5402(75.34 \%)
$$

$2750(78.10 \%)$

$2166(72.66 \%)$

$138(77.53 \%)$

$348(71.02 \%)$

With measurement

$\begin{array}{llllll}N(\%) & 4068(75.31 \%) & 2059(74.87 \%) & 1645(75.95 \%) & 106(76.81 \%) & 258(74.14 \%) \\ \text { HbAlc [\%], mean (SD) } & 7.44(1.07) & 7.46(1.12) & 7.43(1.02) & 7.44(1.20) & 7.29(0.88) \\ \text { HbAlc }<7.5 \%, N(\%) & 2,522(62.00 \%) & 1,247(60.56 \%) & 1,034(62.86 \%) & 67(63.21 \%) & 174(67.44 \%)\end{array}$

Change at 12 months (for patients with recorded values at initiation and month 12)

Mean $\triangle \mathrm{HbA1c}[\%],(\mathrm{SD}) \quad-0.88(1.07) \quad-0.97(1.11) \quad-0.74(1.00) \quad-0.99(1.23) \quad-1.08(0.98)$

DPP4i dipeptidyl peptidase 4 inhibitor, $H b A 1$ glycated haemoglobin, $S D$ standard deviation, $S G L T 2 i$ sodium-glucose transport protein 2 inhibitor, $S U$ sulphonylurea, $T Z D$ thiazolidinedione

a Closest value to month $6, \pm 3$ months)

b Closest value to month $12, \pm 3$ months)

for whom only modest improvements in HbA1c were required, i.e. at the point escalation where treatment is currently recommended (HbA1c $7.5 \%)$, there was no clinically meaningful difference in the benefit achieved by drug class at 6 or 12 months post-baseline. Therefore, predictors of improvement were explored, with the intention of informing identification of the right drug for the right person with T2DM.

\section{Treatment Discontinuation}

Treatment discontinuation rates were highest for people with T2DM receiving SGLT2i at second line with a greater percentage of people receiving SGLT2i switching treatment at 6 months (7.55\%) and 12 months (11.22\%) compared with people prescribed other secondline treatments (6 months: $2.25-4.13 \%$; 


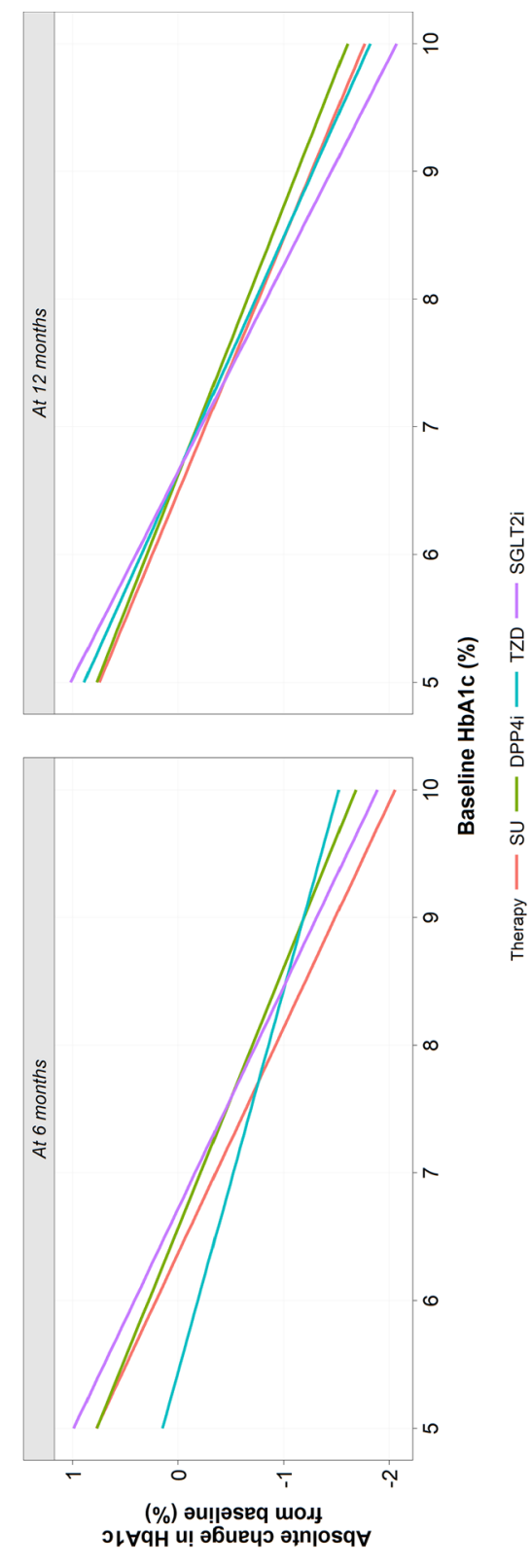

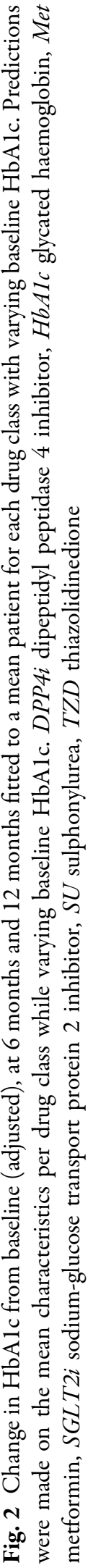

12 months: $5.28-7.98 \%)$. More people prescribed DPP4i or SGLT2i at second-line required escalation of treatment (addition of another drug) $(8.45 \%$ and $6.73 \%$ by month 12 respectively) compared with those receiving SUs or TZDs (2.78\% and 3.93\% respectively) (Table S2).

\section{Adverse Events}

Given the limitations of database analysis, adverse events reported in this study may not be directly attributable to the drugs of interest (Table S3). Fracture risk was highest with SGLT2i and SUs. Retinopathy was higher than previously reported in those treated with TZDs at 252.87 events per 1000 patient years [31]. Unexpectedly, congestive cardiac failure was notably lower in people treated with TZDs, probably reflecting a selection bias in this realworld data set.

\section{Treatment Adherence}

The percentage of people who were non-adherent to second-line therapy was similar for SUs, SGLT2i and TZDs, with 5.77\%, 5.10\% and $5.06 \%$ of people in each drug class having an $\mathrm{MPR}<80 \%$. In comparison, fewer people prescribed DPP4i were non-adherent as $3.84 \%$ had an $\mathrm{MPR}<80 \%$. At 12 months after baseline, MPR $\geq 80 \%$ was associated with greater improvement in HbA1c compared with MPR < $80 \%$ for all drug classes (Figure S3). This was most noticeable for treatment with SUs, SGLT2i and TZDs.

\section{DISCUSSION}

The results of this study demonstrate, using a real-world population, that similar percentages of people who received each of the four classes of second-line OHAs achieved the recommended HbA1c target of $<7.5 \%$ (58 $\mathrm{mmol} / \mathrm{mol})$. This study also demonstrated that there are trends in HbA1c response associated with different phenotypes. All second-line OHAs appeared to be well tolerated with low 
rates of non-adherence. Across all drug classes, people with higher MPR $(\geq 80 \%)$ also had greater improvements in HbA1c at 12 months post-baseline, especially those on drugs other than DPP4i.

With a range of second-line therapy options available after metformin monotherapy for T2DM, and lack of definitive clinical guidance on the most appropriate drug to prescribe, clinicians may be uncertain regarding the optimal treatment for any given patient. Paradoxically, the lack of certainty has resulted in a rise in the HbA1c at which second-line therapies are introduced [32]. Whereas the glycaemic effects of T2DM second-line drugs on HbA1c levels have been examined in clinical studies, the clinical implication of these studies is limited by the small study numbers and homogeneity of the study populations. Meta-analyses of clinical trials may be better powered and more generalisable, but they are limited by publication bias, small study effects and limited degree of heterogeneity. This study is the first to provide real-world evidence comparing the relative effectiveness of SUs, TZDs, DPP4i and SGLT2i after metformin for glycaemic control according to a person's phenotypic characteristics at second-line initiation. It is important to note that we deliberately excluded populations in whom certain agents had a demonstrated benefit in CVOTs (such as proven atherosclerosis or heart failure) to focus solely on the population for which there is prescriptive uncertainty. The study found very little difference in the glycaemic effects of these OHAs, reflecting findings reported in recent systematic reviews and metaanalyses [27, 33]. However, the results demonstrated that for certain sub-groups, a particular drug class may be more beneficial.

The results of this study suggest that SGLT2i may be an appropriate treatment choice at second line for males with T2DM who are relatively young, with lower BMI and higher DBP, as individuals with these characteristics achieved a greater improvement in HbA1c compared with individuals without such characteristics. The data further demonstrated that relatively older males with lower BMI and lower eGFR are likely to benefit from SUs at secondline, potentially an effect of accumulation due to renal failure and insulin resistance burn out that occurs with ageing as sarcopaenia ensues. While the data appeared to display associations between these phenotypic characteristics and HbA1c improvement, only the trends in age for SGLT2i and SUs were statistically significant. In a randomised controlled trial setting, females with T2DM and relatively high BMI achieved better response with TZDs but the same effect was not found using data from real-world clinical practice [32]. This may potentially be due to the relatively small number of people on TZDs in this study. The effect of DPP4i on glycaemic control was consistent irrespective of baseline characteristics; therefore, DPP4i may be used for people with T2DM who do not fit the characteristics for another class and therefore would not be expected to accrue as much benefit from alternative agents.

A similar real-world evidence study, the international EDGE (Effectiveness of Diabetes control with vildaGliptin and vildagliptin/ mEtformin) study, prospectively compared the efficacy and safety of the DPP4i vildagliptin with other OHAs in people with T2DM not adequately controlled on monotherapy. The results demonstrated that in a real-world setting, vildagliptin as a second drug can lower HbA1c without well-recognised side effects more frequently than comparator OHAs [34]. It has been hypothesised that the reason for these differences in the EDGE trial, where the predominant comparator was SUs, was differences in adherence. It has been suggested that participants in that particular study who experienced a hypoglycaemic episode would be more likely to discontinue or have a lower adherence to therapy than their counterparts who did not experience such adverse events on DPP4i. Our population used more modern SUs (with a lower risk of hypoglycaemia), which may be why this difference was not consistently observed, although slightly fewer people on DPP4i compared with other drug classes had a MPR $<80 \%$. An alternative explanation may be the difference between prescribing strategies in clinical trials, where the optimum dose of agent is commenced within a few weeks, and clinical practice, where doses are escalated slowly 
dependent on response and observed hypoglycaemia.

In this study, there is the possibility of confounding by indication as treatments were selected based on clinical judgement according to specific patient characteristics. This nonrandom selection resulted in differences between the baseline characteristics of the treatment groups, although multivariate regression was undertaken to adjust for these differences. Additionally, not all relevant confounding factors are captured in CPRD, and the analyses may have been affected by the quality and completeness of original data entry. However, key factors such as age and comorbidities that have previously been identified [30, 32] were accounted for in this study. Further potential limitations of this study include medical records showing prescriptions rather than medication use, and therefore analyses assume patient adherence to their medication, which in turn is likely to over-estimate MPR. The strict study inclusion criteria included individuals in the analysis if they received one repeat prescription and consequently people who discontinued therapy after the first prescription (for example, because of candidiasis whilst receiving an SGLT2i, hypoglycaemia when receiving $S U$ therapy or an exacerbation of their heart failure on a TZD) were not quantified in this analysis. Regarding the analysis of AEs, with CPRD data it is difficult to determine truly incident events because of the nature of the coding (ongoing or historical events may be incorrectly recorded as new events). Incident cases within the study period have been included, but it should be noted that this may include pre-existing conditions.

In summary, this study has identified phenotypic characteristics that have the potential to influence individual treatment response. Accounting for these characteristics in clinical treatment decisions may improve therapy selection and the outcomes of individual patients. Additional studies are needed to verify the predictive value of these factors and to determine their clinical utility.

\section{CONCLUSION}

The evidence from this study can potentially be used to support better targeting of second-line T2DM therapy. The choice of which drug to offer after metformin should be based on the individual person's phenotypic characteristics (including gender, age, BMI, eGFR and duration of T2DM), considering their treatment goals, extent of hyperglycaemia, comorbidities and the beneficial and adverse effects of each class of drug to select the right drug for the right patient.

\section{ACKNOWLEDGEMENTS}

The views expressed in this publication are those of the author(s) and not necessarily those of the NIHR Exeter Clinical Research Facility, the NHS, the NIHR or the Department of Health in England.

Funding. Sponsorship for this work and the Rapid Service Fee were funded by Takeda UK Ltd.

Editorial and Other Assistance. The authors thank Dr Angharad R. Morgan of Health Economics and Outcomes Research Ltd. for editorial assistance in the preparation of this manuscript and Louise Hoskin and John Houghton of Health Economics and Outcomes Research Ltd. for assistance with statistical analyses. Support for this assistance was funded by Takeda UK Ltd.

Authorship. All named authors meet the International Committee of Medical Journal Editors (ICMJE) criteria for authorship for this article, take responsibility for the integrity of the work as a whole, and have given their approval for this version to be published.

Disclosures. Carmen Tsang, Michael Hurst and Phil McEwan are employees of Health Economics and Outcomes Research (HEOR) Ltd., Cardiff, UK. HEOR Ltd. received fees from Takeda Pharmaceuticals in relation to this 
study. Minesh Unadkat, Simon Meadowcroft and Richard Shardlow are employees of Takeda Pharmaceuticals. William D. Strain received an honorarium from Takeda for work on this study. He also holds research grants from Bayer, Novo Nordisk and Novartis and has received speaker honoraria from AstraZeneca, Bayer, Bristol-Myers Squibb, Merck, Napp, Novartis, Novo Nordisk and Takeda. William D. Strain is supported by the NIHR Exeter Clinical Research Facility and the NIHR Collaboration for Leadership in Applied Health Research and Care (CLAHRC) for the South West Peninsula. Marc Evans received an honorarium from Takeda for work on this study. He has received honoraria and research awards from Novo Nordisk, AstraZeneca, Novartis, BI and Sunovion. Marc Evans is also the Editor-in-Chief of this journal.

Compliance with Ethics Guidelines. This was a retrospective observational study using anonymised data from CPRD, which holds ethical approval for observational studies. The Independent Scientific Advisory Committee for Medicines and Healthcare Products Regulatory Agency approved this study (19_078RAR). Subsequent amendments were approved by ISAC on 18 March 2020 (ISAC protocol reference 19_078RAR).

Data Availability. The data that support the findings of this study are available from the UK Clinical Practice Research Datalink (CPRD), https://www.cprd.com/home/.

Open Access. This article is licensed under a Creative Commons Attribution-NonCommercial 4.0 International License, which permits any non-commercial use, sharing, adaptation, distribution and reproduction in any medium or format, as long as you give appropriate credit to the original author(s) and the source, provide a link to the Creative Commons licence, and indicate if changes were made. The images or other third party material in this article are included in the article's Creative Commons licence, unless indicated otherwise in a credit line to the material. If material is not included in the article's Creative Commons licence and your intended use is not permitted by statutory regulation or exceeds the permitted use, you will need to obtain permission directly from the copyright holder. To view a copy of this licence, visit http://creativecommons.org/licenses/by$\mathrm{nc} / 4.0 /$.

\section{REFERENCES}

1. Sacks DB. Hemoglobin A1c in diabetes: panacea or pointless? Diabetes. 2013;62(1):41-3. https://doi. org/10.2337/db12-1485 (Epub 22 Dec 2012. PubMed PMID: 23258914; PubMed Central PMCID: PMCPMC3526051).

2. Litwak L, Goh SY, Hussein Z, Malek R, Prusty V, Khamseh ME. Prevalence of diabetes complications in people with type 2 diabetes mellitus and its association with baseline characteristics in the multinational A1chieve study. Diabetol Metab Syndr. 2013;5(1):57. https://doi.org/10.1186/17585996-5-57 (Epub 16 Nov 2013. PubMed PMID: 24228724; PubMed Central PMCID: PMCPMC3854020).

3. Zheng Y, Ley SH, Hu FB. Global aetiology and epidemiology of type 2 diabetes mellitus and its complications. Nat Rev Endocrinol. 2018;14(2):88-98. https://doi.org/10.1038/nrendo.2017.151 (Epub 9 Dec 2017. PubMed PMID: 29219149).

4. Holmes J, McGill S, Kind P, Bottomley J, Gillam S, Murphy M. Health-related quality of life in type 2 diabetes (TARDIS-2). Value Health. 2000;3(Suppl 1): 47-51. https://doi.org/10.1046/j.1524-4733.2000. 36028.x (Epub 9 Feb 2006. PubMed PMID: 16464209).

5. Luckie R, Leese G, McAlpine R, MacEwen CJ, Baines PS, Morris AD, et al. Fear of visual loss in patients with diabetes: results of the prevalence of diabetic eye disease in Tayside, Scotland (P-DETS) study. Diabetic Med. 2007;24(10):1086-92. https://doi. org/10.1111/j.1464-5491.2007.02180.x (Epub 25 Sept 2007. PubMed PMID: 17888131).

6. Kuniss N, Freyer M, Muller N, Kielstein V, Muller UA. Expectations and fear of diabetes-related longterm complications in people with type 2 diabetes at primary care level. Acta Diabetol. 2019;56(1): 33-8. https://doi.org/10.1007/s00592-018-1217-9 (Epub 31 Aug 2018. PubMed PMID: 30159745).

7. Hendricks LE, Hendricks RT. Greatest fears of type 1 and type 2 patients about having diabetes: implications for diabetes educators. Diabetes Educ. 1998;24(2):168-73. https://doi.org/10.1177/ 014572179802400206 (Epub 29 Apr 1998. PubMed PMID: 9555355). 
8. National Institute for Health and Care Excellence. NICE guideline [NG28]: Type 2 diabetes in adults: management 2015. https://www.nice.org.uk/ guidance/ng28. Accessed 12 Feb 2020.

9. American Diabetes Association. Standards of medical care in diabetes-2020. Diabetes Care. 2020;43(Suppl 1):S1-S212.

10. UK Prospective Diabetes Study (UKPDS) Group. Effect of intensive blood-glucose control with metformin on complications in overweight patients with type 2 diabetes (UKPDS 34). Lancet. 1998;352(9131):854-65 (Epub 22 Sept 1998. PubMed PMID: 9742977).

11. UK Prospective Diabetes Study (UKPDS) Group. Intensive blood-glucose control with sulphonylureas or insulin compared with conventional treatment and risk of complications in patients with type 2 diabetes (UKPDS 33). Lancet. 1998;352(9131):837-5365 (Epub 22 Sept 1998. PubMed PMID: 9742976).

12. Holman RR, Paul SK, Bethel MA, Matthews DR, Neil HA. 10-year follow-up of intensive glucose control in type 2 diabetes. N Engl J Med. 2008;359(15): 1577-89. https://doi.org/10.1056/NEJMoa0806470 (Epub 12 Sept 2008. PubMed PMID: 18784090).

13. Patel A, MacMahon S, Chalmers J, Neal B, Billot L, Woodward M, et al. Intensive blood glucose control and vascular outcomes in patients with type 2 diabetes. N Engl J Med. 2008;358(24):2560-72. https:// doi.org/10.1056/NEJMoa0802987 (Epub 10 June 2008. PubMed PMID: 18539916).

14. King P, Peacock I, Donnelly R. The UK prospective diabetes study (UKPDS): clinical and therapeutic implications for type 2 diabetes. Br J Clin Pharmacol. 1999;48(5):643-8. https://doi.org/10.1046/j. 1365-2125.1999.00092.x (Epub 14 Dec 1999. PubMed PMID: 10594464; PubMed Central PMCID: PMCPMC2014359).

15. Ohkubo Y, Kishikawa H, Araki E, Miyata T, Isami S, Motoyoshi $S$, et al. Intensive insulin therapy prevents the progression of diabetic microvascular complications in Japanese patients with non-insulin-dependent diabetes mellitus: a randomized prospective 6-year study. Diabetes Res Clin Pract. 1995;28(2):103-17. https://doi.org/10.1016/01688227(95)01064-k (Epub 1 May 1995. PubMed PMID: 7587918).

16. Stratton IM, Adler AI, Neil HA, Matthews DR, Manley SE, Cull CA, et al. Association of glycaemia with macrovascular and microvascular complications of type 2 diabetes (UKPDS 35): prospective observational study. BMJ (Clin Res Ed). 2000;321(7258):405-12. https://doi.org/10.1136/ bmj.321.7258.405 (Epub 11 Aug 2000. PubMed
PMID: 10938048; PubMed Central PMCID: PMCPMC27454).

17. Casanova F, Adingupu DD, Adams F, Gooding KM, Looker HC, Aizawa K, et al. The impact of cardiovascular co-morbidities and duration of diabetes on the association between microvascular function and glycaemic control. Cardiovasc Diabetol. 2017;16(1):114. https://doi.org/10.1186/s12933017-0594-7 (Epub 17 Sept 2017. PubMed PMID: 28915818; PubMed Central PMCID: PMCPMC5603035).

18. Rojas LB, Gomes MB. Metformin: an old but still the best treatment for type 2 diabetes. Diabetol Metab Syndr. 2013;5(1):6. https://doi.org/10.1186/ 1758-5996-5-6 (Epub 19 Feb 2013. PubMed PMID: 23415113; PubMed Central PMCID: PMCPMC3607889).

19. Scarpello JH, Howlett HC. Metformin therapy and clinical uses. Diabetes Vasc Dis Res. 2008;5(3): 157-67. https://doi.org/10.3132/dvdr.2008.027 (Epub 9 Sept 2008. PubMed PMID: 18777488).

20. Buse JB, Wexler DJ, Tsapas A, Rossing P, Mingrone G, Mathieu C, et al. 2019 update to: Management of hyperglycaemia in type 2 diabetes, 2018. A consensus report by the American Diabetes Association (ADA) and the European Association for the Study of Diabetes (EASD). Diabetologia. 2020;63(2):221-8. https://doi.org/10.1007/s00125-019-05039-w (Epub 20 Dec 2019. PubMed PMID: 31853556).

21. Green JB, Bethel MA, Armstrong PW, Buse JB, Engel SS, Garg J, et al. Effect of sitagliptin on cardiovascular outcomes in type 2 diabetes. N Engl J Med. 2015;373(3):232-42. https://doi.org/10.1056/ NEJMoa1501352 (Epub 9 June 2015. PubMed PMID: 26052984).

22. Scirica BM, Bhatt DL, Braunwald E, Steg PG, Davidson J, Hirshberg B, et al. Saxagliptin and cardiovascular outcomes in patients with type 2 diabetes mellitus. N Engl J Med. 2013;369(14): 1317-26. https://doi.org/10.1056/NEJMoa1307684 (Epub 3 Sept 2013. PubMed PMID: 23992601).

23. Neal B, Perkovic V, Mahaffey KW, de Zeeuw D, Fulcher G, Erondu N, et al. Canagliflozin and cardiovascular and renal events in type 2 diabetes. N Engl J Med. 2017;377(7):644-57. https://doi.org/ 10.1056/NEJMoa1611925 (Epub 13 June 2017. PubMed PMID: 28605608).

24. Wiviott SD, Raz I, Bonaca MP, Mosenzon O, Kato ET, Cahn A, et al. Dapagliflozin and cardiovascular outcomes in type 2 diabetes. $\mathrm{N}$ Engl J Med. 2019;380(4):347-57. https://doi.org/10.1056/ NEJMoa1812389 (Epub 13 Nov 2018. PubMed PMID: 30415602). 
25. Monami M, Lamanna C, Marchionni N, Mannucci E. Comparison of different drugs as add-on treatments to metformin in type 2 diabetes: a metaanalysis. Diabetes Res Clin Pract. 2008;79(2): 196-203. https://doi.org/10.1016/j.diabres.2007.08. 024 (Epub 13 Oct 2007. PubMed PMID: 17931733).

26. Phung OJ, Scholle JM, Talwar M, Coleman CI. Effect of noninsulin antidiabetic drugs added to metformin therapy on glycemic control, weight gain, and hypoglycemia in type 2 diabetes. JAMA. 2010;303(14):1410-8. https://doi.org/10.1001/ jama.2010.405 (Epub 15 Apr 2010. PubMed PMID: 20388897).

27. McIntosh B, Cameron C, Singh SR, Yu C, Ahuja T, Welton NJ, et al. Second-line therapy in patients with type 2 diabetes inadequately controlled with metformin monotherapy: a systematic review and mixed-treatment comparison meta-analysis. Open Med. 2011;5(1):e35-48 (Epub 3 Nov 2011. PubMed PMID: 22046219; PubMed Central PMCID: PMCPMC3205809).

28. Herrett E, Gallagher AM, Bhaskaran K, Forbes H, Mathur R, van Staa T, et al. Data resource profile: clinical practice research datalink (CPRD). Int $\mathrm{J}$ Epidemiol. 2015;44(3):827-36. https://doi.org/10. 1093/ije/dyv098 (Epub 8 June 2015. PubMed PMID: 26050254; PubMed Central PMCID: PMCPMC4521131).

29. Gordon J, McEwan P, Idris I, Evans M, Puelles J. Treatment choice, medication adherence and glycemic efficacy in people with type 2 diabetes: a UK clinical practice database study. BMJ Open Diabetes Res Care. 2018;6(1):e000512. https://doi.org/10. 1136/bmjdrc-2018-000512 (Epub 15 May 2018. PubMed PMID: 29755756; PubMed Central PMCID: PMCPMC5942418).

30. Shields BM, Hattersley AT, Farmer AJ. Identifying routine clinical predictors of non-adherence to second-line therapies in type 2 diabetes: a retrospective cohort analysis in a large primary care database. Diabetes Obes Metab. 2020;22(1):59-655. https://doi.org/10.1111/dom.13865 (Epub 31 Aug 2019. PubMed PMID: 31468676; PubMed Central PMCID: PMCPMC6916179).

31. Wang T, Hong JL, Gower EW, Pate V, Garg S, Buse $\mathrm{JB}$, et al. Incretin-based therapies and diabetic retinopathy: real-world evidence in older U.S. adults. Diabetes Care. 2018;41(9):1998-2009. https://doi.org/10.2337/dc17-2285 (Epub 18 July 2018. PubMed PMID: 30012674; PubMed Central PMCID: PMCPMC6105327).

32. Dennis JM, Henley WE, McGovern AP, Farmer AJ, Sattar N, Holman RR, et al. Time trends in prescribing of type 2 diabetes drugs, glycaemic response and risk factors: a retrospective analysis of primary care data, 2010-2017. Diabetes Obes Metab. 2019;21(7):1576-84. https://doi.org/10. 1111/dom.13687 (Epub 5 Mar 2019. PubMed PMID: 30828962; PubMed Central PMCID: PMCPMC6618851).

33. Bennett WL, Maruthur NM, Singh S, Segal JB, Wilson LM, Chatterjee R, et al. Comparative effectiveness and safety of medications for type 2 diabetes: an update including new drugs and 2-drug combinations. Ann Intern Med. 2011;154(9):602-13. https://doi.org/10.7326/0003-4819-154-9-

201105030-00336 (Epub 16 Mar 2011. PubMed PMID: 21403054; PubMed Central PMCID: PMCPMC3733115).

34. Mathieu C, Barnett AH, Brath H, Conget I, de Castro JJ, Goke R, et al. Effectiveness and tolerability of second-line therapy with vildagliptin vs. other oral agents in type 2 diabetes: a real-life worldwide observational study (EDGE). Int J Clin Pract. 2013;67(10):947-56. https://doi.org/10.1111/ijcp. 12252 (Epub 22 Aug 2013. PubMed PMID: 23961850; PubMed Central PMCID: PMCPMC4231206). 